\title{
EDITORIAL
}

\section{To the rescue of bats}

\author{
Plans by several US federal agencies to fight the rapid spread of white-nose syndrome in \\ bats are to be welcomed, but the benefits of further basic research into the causative agent \\ should not be ignored.
}

For those of us currently sheltering from cold winter weather in our cosy homes and offices, spare a thought for the bats of the eastern United States, which are under attack by a deadly killer disease, white-nose syndrome, during their hibernation. This disease was first seen in 2006 in a cave in upstate New York, USA, but was not recognized as such a serious problem until a year later. Even at this early stage, reports indicated how devastating the disease can be, with the mortality rate for individual caves often reaching $100 \%$. The disease has moved rapidly along the east coast of the United States and was recently detected as far west as Oklahoma, raising fears that the entire bat population of North America may soon be at risk. Thus far, six bat species have fallen victim to this disease, with the small brown bat the most severely affected. Interestingly, some bat species appear to be infected but do not show any overt symptoms. It is estimated that more than 1 million bats have been killed by this disease since the beginning of the outbreak, making this one of the most serious wildlife crises that we face, given the important role of bats in the ecosystem, and the future does not look bright.

The cause of white-nose syndrome was discovered in 2008: it is a newly described pathogen, the psychrophilic fungus Geomyces destructans. Little is known about G. destructans, as it had not been identified prior to its isolation from infected bats. It has since also been detected in several countries in Europe but is not associated with mortality there. The fungus appears to be well suited to being a pathogen of bats. It thrives at low temperatures $\left(0-15^{\circ} \mathrm{C}\right.$, the body temperature of hibernating bats) and prefers the same humid conditions in which the bats hibernate. Bats tend to aggregate while hibernating, allowing easy transmission of the disease, and their immune system is downregulated during this time, making them susceptible to infection. Although the most obvious symptom of the disease is the white nose (a result of the build-up of conidia), it is likely that infection of the wings leads to a disturbance in the water balance of the animal. This disturbs the torpor of hibernation and induces increased activity during a time when no food is available, ultimately leading to death by starvation.
Fully appreciating the severity of this new bat disease, several US federal agencies have recently released a draft plan to assist states, federal agencies and Native American tribes in managing the disease. The plan advocates setting up several working groups to handle tasks such as disseminating information to the public, setting up surveillance standards, providing information on conservation and recovery, and standardizing the diagnosis of the disease; it also provides extensive guidance on measures to prevent the further spread of the disease, including the use of protective clothing and the closure of some caves to humans. These steps are likely to help slow or stop the spread of the disease, and it is heartening to see this problem receive such serious treatment.

However, one element missing from the report is a call to further investigate the fungus. This fungus and bats have coexisted for a long time, especially in Europe, making it unclear what factors led to the sudden outbreak of bat infections. An understanding of the aspects of the fungus that drive its pathogenicity, and its apparently recent jump into the bat host in North America, is likely to uncover basic properties that will not only be useful for diagnostics and surveillance of future outbreaks, but also inform potential intervention strategies to halt the spread of the disease. This is especially important in the light of two other outbreaks of animal epidemics that also arose rapidly and have devastated populations: the infection of amphibians by the chytrid fungus Batrachochytrium dendrobatidis and the decline in the bee population due to colony collapse disorder (thought to be the result, in part, of infection with the microsporidium Nosema ceranae). Although the pathogens are different, the rapid spread of the outbreaks and their effects on the host populations are similar. The damage caused by these outbreaks to ecosystems and animal populations is enormous and will have a knock-on effect on agriculture, industry and, consequently, human health. Therefore, investigating these outbreaks and the pathogens should be the highest priority this year.

\section{FURTHER INFORMATION}

US federal agencies' draft plan: http://www.fws.gov/whitenosesyndrome/ pdf/WNSNational Plan DRAFT 10.21.2010.pdf

ALL LINKS ARE ACTIVE IN THE ONLINE PDF 